\title{
Intergranular Fatigue Crack Initiation and Its Associated Small Fatigue Crack Propagation in Water-quenched Fe-C Fully Ferritic Steel
}

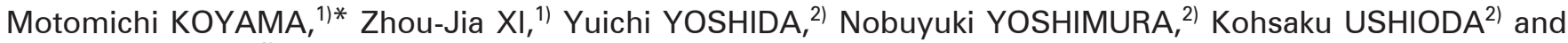 \\ Hiroshi NOGUCHI ${ }^{1)}$ \\ 1) Faculty of Engineering, Kyushu University, 744 Moto-oka, Nishi-ku, Fukuoka-shi, Fukuoka, 819-0395 Japan. \\ 2) Plate \& \\ Shape Research Laboratories, Nippon Steel \& Sumitomo Metal Corporation, 20-1 Shintomi, Futtsu, Chiba, $293-8511$ Japan.
}

(Received on June 1, 2015; accepted on July 14, 2015)

\begin{abstract}
The fatigue crack initiation and propagation behavior of a water-quenched binary Fe-C fully ferritic steel was investigated though rotating-bending fatigue testing. Intergranular and transgranular crack initiation and propagation were observed. The intergranular crack propagation did not stop, while the transgranular crack propagation was retarded by crack closure and strain aging. As a result, intergranular cracking was the dominant cause of fatigue damage in the steel. A considerable number of cracks were initiated; these propagated through coalescence, which occurred mainly at the grain boundaries. Dominancy of the intergranular fatigue crack propagation increased with increasing stress amplitude. In addition, the steel showed coaxing effect significantly. The coaxing effect suppresses crack initiation as well as crack propagation.
\end{abstract}

KEY WORDS: small fatigue crack; nonpropagating fatigue crack; low-carbon steel; intergranular cracking; coaxing effect.

\section{Introduction}

The importance of fatigue damage has been recognized widely, and the phenomenon has been investigated extensively, particularly in steels. Those researches elucidated various fatigue crack initiation and propagation mechanisms. However, some factors affecting the evolution mechanisms of fatigue damage have not been fully understood yet, even in the case of conventional ferritic steels. Therefore, the associated fatigue properties, including the large degree of scatter, have to be evaluated statistically. This is the reason why high safety factors are required for structural materials, as these factors allow for the practical use of newly developed high-strength steels. To control the fatigue properties of such steels, with the aim of lowering the safety rate, it is essential to theoretically understand the primary factors causing the uncertainty of fatigue lives.

In fact, fatigue damage evolution process consists of two parts: fatigue crack initiation and propagation. Even in a plain specimen of annealed carbon steel, approximately $70 \%$ of fatigue life is occupied by the fatigue crack propagation life. ${ }^{1)}$ Furthermore, the fatigue crack propagation is classified into small and long crack regimes. Abovementioned scatter in fatigue properties is mainly caused by phenomena associated with small cracks. The term of "small crack"2-4) in fatigue phenomenon is defined by various viewpoints:

* Corresponding author: E-mail: koyama@mech.kyushu-u.ac.jp DOI: http://dx.doi.org/10.2355/isijinternational.ISIJINT-2015-305
I) mechanically-small crack, ${ }^{1,5)}$ II) microstructurally-small crack, ${ }^{6}$ III) physically-small crack, ${ }^{7-9)}$ and IV) chemicallysmall crack. ${ }^{10)}$ The respective small cracks can be classified by corresponding "length" where each specific main factor affects propagation behavior. For instance, a maximum length of the chemically-small crack is $\sim 10 \mathrm{~mm}^{2)}$ In contrast, the maximum microstructurally-small crack length is related to grain size, which is the totally different scale ranging from a few tens of $\mu \mathrm{m}$ to several hundreds of $\mu \mathrm{m} .{ }^{2}{ }^{2}$ Here note that engineering materials and structures have many stress concentration sources such as inclusion and small scratches with sizes ranging from a few tens of $\mu \mathrm{m}$ to several hundreds of $\mu \mathrm{m}$. Thus, it is crucial to evaluate the microstructurally and mechanically small fatigue crack propagation behavior, ${ }^{11)}$ whose characteristics are different from those of a large crack analysed by compact tension testing.

From a metallurgical point of view, the scatter in the fatigue properties associated with microstructurally small crack propagation is considered to stem from the microstructural characteristics of the steel in question ${ }^{12-14)}$ and from solute atom diffusion/segregation. ${ }^{15-17)}$ More specifically, chemical composition affecting microstructure and strength plays a key role on the microstructurally-small fatigue crack propagation behavior. In particular, carbon is the most important element in fatigue of steels. Therefore, carbon-related phenomena such as carbide formation and carbon segregation are the important factors in fatigue of steels. For instance, in terms of the microstructure, we found 
that the existence of a cementite morphology has a marked effect on the small fatigue crack propagation behavior of ferritic steels as well as on their fatigue strength. ${ }^{18)}$ In contrast, the other factor, namely, carbon atom diffusion/ segregation, has not been investigated as extensively. In the case of steels, at least, it has been reported that the strain age hardening of carbon at a vicinity of a crack tip enhances nonpropagating fatigue crack phenomenon. ${ }^{15)}$

However, the correlation between carbon atom diffusion/segregation and microstructurally-small fatigue crack propagation has not yet been elucidated. More specifically, there have been no studies on $\mathrm{Fe}-\mathrm{C}$ binary steels that have a single ferritic phase, which corresponds to the simplest chemical composition and microstructure in steels. Since carbon is the most important solute element in steels, understanding the effects of carbon as a solute, including its effect on strain aging, is critical for achieving a theoretical understanding of the fatigue properties. In this study, we aimed to elucidate the underlying effects of solute carbon and its correlation to small fatigue crack propagation using a ferritic $\mathrm{Fe}-\mathrm{C}$ binary steel.

\section{Experimental Procedure}

\subsection{Material}

As mentioned above, for the sake of simplicity, we prepared a binary $\mathrm{Fe}-\mathrm{C}$ ferritic steel that did not contain a cementite or pearlite phase. The chemical composition of the steel was as follows: $\mathrm{C}=0.017, \mathrm{Si} \leq 0.003, \mathrm{Mn} \leq 0.003$, $\mathrm{P} \leq 0.002, \mathrm{~S} \leq 0.0003, \mathrm{~T} i \leq 0.002, \mathrm{Al}=0.052$, and $\mathrm{N}=0.0009$ (wt.\%). The specimens were solution-treated at $700^{\circ} \mathrm{C}$ for $3.6 \mathrm{ks}$ and subsequently water-quenched to suppress cementite formation and carbon segregation at grain boundaries. The heat-treated specimens had a grain size of approximately $65 \mu \mathrm{m}$. The specimens were preserved in refrigerator at $-87^{\circ} \mathrm{C}$ at all times except during sample preparation and testing to inhibit uncontrolled grain boundary carbon segregation at room temperature, although the segregation would occur during the sample preparation. The mechanical properties are listed in Table 1; these properties were measured by tensile testing at room temperature at a nominal strain rate of $10^{-3} \mathrm{~s}^{-1}$. Bar specimens for the tensile and rotating-bending fatigue tests, shown in Fig. 1, were produced using a lathe. The specimens were mechanically polished and subsequently etched with a mixture of $3 \%$ nitric acid and 97\% ethanol (vol\%).

\subsection{Fatigue Testing}

The rotating-bending fatigue tests were performed at ambient temperature $(298 \mathrm{~K})$ at a frequency of $50 \mathrm{~Hz}$. The stress ratio, $R$, was -1 , and a sinusoidal waveform was employed. The fatigue limit was assumed to be the highest stress amplitude at which the specimen did not fail

Table 1. Tensile mechanical properties used in this study. These properties are average values of three tests.

\begin{tabular}{cccc}
\hline $\begin{array}{c}\text { Upper yield } \\
\text { strength }\end{array}$ & $\begin{array}{c}\text { Lower yield } \\
\text { strength }\end{array}$ & $\begin{array}{c}\text { Ultimate } \\
\text { tensile strength }\end{array}$ & Elongation \\
\hline $305 \mathrm{MPa}$ & $281 \mathrm{MPa}$ & $406 \mathrm{MPa}$ & $27 \%$ \\
\hline
\end{tabular}

after $10^{7}$ cycles. The plastic one-step replica method was employed to measure fatigue crack length. A $34-\mu$ m-thick acetyl cellulose film was used for replication. The replica sheet was immersed in methyl acetate prior to being placed on the specimen surface. The lengths of the fatigue cracks were measured from the optical microscopy images of the replicas.

Moreover, a degree of coaxing effect in the present steel was investigated. The coaxing effect is a phenomenon strengthening fatigue strength through prior cyclic deformation at a lower stress level. The coaxing effect was reported in a mild steel whose fatigue limit was $252 \mathrm{MPa}{ }^{19)}$ When the stress amplitude was increased from just below the fatigue limit in regular steps of $3 \mathrm{MPa}$ every $10^{7}$ cycles, the mild steel specimen did not show failure until the stress amplitude of $325 \mathrm{MPa}$. Early systematic studies on coaxing effect have been performed by Kommers ${ }^{20)}$ and Bennett. ${ }^{21)}$ Note that the coaxing effect in most cases has been found in metallic materials where strain age hardening occurs significantly, ${ }^{22)}$ except for austenitic stainless steels. ${ }^{23,24)}$ More specifically, the coaxing effect in carbon steels is considered to stem from non-propagating fatigue crack phenomenon associated with strain age hardening. Hence, many researches ${ }^{24-28)}$ have studied the small fatigue cracking behavior to understand the coaxing effect in the crack propagation portion of fatigue lives. Therefore, in this study, after $10^{7}$ cycles at the fatigue limit of the present steel, the stress amplitude was increased by $5 \mathrm{MPa}$ every $10^{7}$ cycles to investigate coaxing effect.

\section{Results and Discussion}

Figure 2 shows the stress amplitude-number of cycles to failure curve. Fatigue limit of the present steel was determined to be $210 \mathrm{MPa}$. Although fatigue cracks were initiated at a grain boundary and propagated to grain interior at $210 \mathrm{MPa}$ after $7 \times 10^{6}$ cycles (Fig. 3(b)), it did not propagate anymore even after $10^{7}$ cycles (Fig. 3(c)), indicating that nonpropagating fatigue cracks occurred in the steel. Namely, the fatigue limit is determined by threshold remote stress for the fatigue crack propagation rather than that for the fatigue crack initiation.

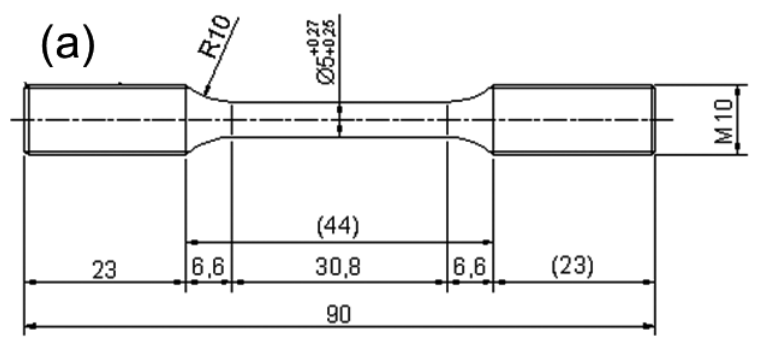

(b)

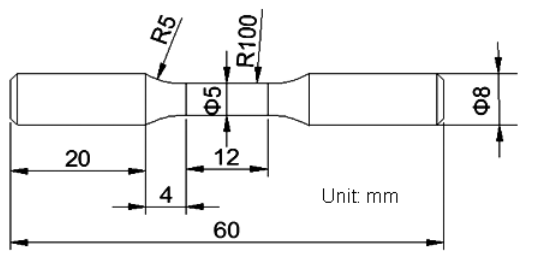

Fig. 1. The schematics for the specimen geometries of (a) tensile and (a) rotary bending fatigue tests. 
After $10^{7}$ cycles at $210 \mathrm{MPa}$, the stress amplitude was increased by $5 \mathrm{MPa}$ every $10^{7}$ cycles to investigate whether the coaxing effect ${ }^{15-17)}$ occurs as shown in Fig. 2. The specimen did not show failure even at $240 \mathrm{MPa}$ which is much higher than the fatigue limit, although the test at 240 $\mathrm{MPa}$ without coaxing effect showed the failure at $1.8 \times 10^{6}$ cycles. Moreover, the crack initiated at $210 \mathrm{MPa}$ did not propagate below $250 \mathrm{MPa}$. This phenomenon is known to stem from the strain age hardening of carbon. ${ }^{15-17)}$ Here note that no other crack was observed except for the crack shown in Fig. 3 even after increasing the stress amplitude to $240 \mathrm{MPa}$. Since the crack initiated at $210 \mathrm{MPa}$ did not propagate, and no new cracks formed at $240 \mathrm{MPa}$, it can be concluded that strain age hardening resulted in both the suppressions of fatigue crack initiation and propagation. The suppression of crack initiation by strain age hardening even at higher stresses highlights an important aspect of the intergranular crack initiation mechanism, namely, that intergranular fatigue cracks are initiated by the localization of plastic strain in the vicinity of grain boundaries and not by stress concentration at grain boundaries. In essence, plastic strain is required for occurrence of strain age hardening. Therefore, had the fatigue crack been initiated by stress concentration, strain aging would not have contributed to increase the resistance to intergranular cracking. Further, the weakest grain boundary would have cracked when the stress amplitude was increased to $225 \mathrm{MPa}$ where the failure was shown before $10^{7}$ cycles. The newly formed crack should

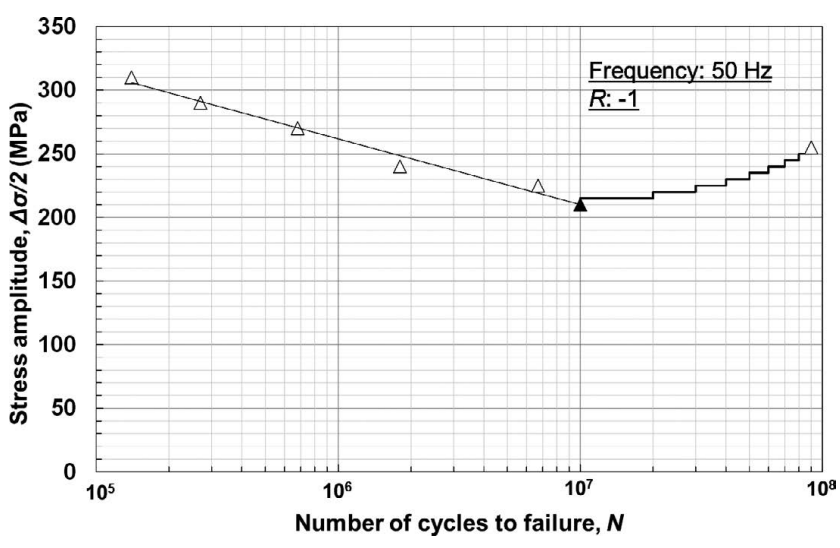

Fig. 2. Stress amplitude-number of cycles diagram. The open marks indicate the fatigue lives of broken specimens. The solid mark indicates unbroken. The steps after the $10^{7}$ cycles indicate the results of the coaxing effect test. have propagated and caused failure at the relatively high stress amplitude. On the other hand, in case that the localization of plastic strain causes the intergranular cracking, the plastic strain localization occurs not to exceed a critical strain for the crack initiation at the fatigue limit, and then strain aging hardens the vicinity of the grain boundaries. As a result, the intergranular cracking does not occur even after increasing stress amplitude. Hence, the intergranular fatigue cracking is concluded to occur through plastic strain localization, although the cracking feature looks brittle.

Figures 4(a) and 4(b) show the fatigue crack length and the corresponding fatigue crack propagation rates at the stress amplitude of $240 \mathrm{MPa}$. No crack was observed before the first plot. Then, intergranular and transgranular fatigue
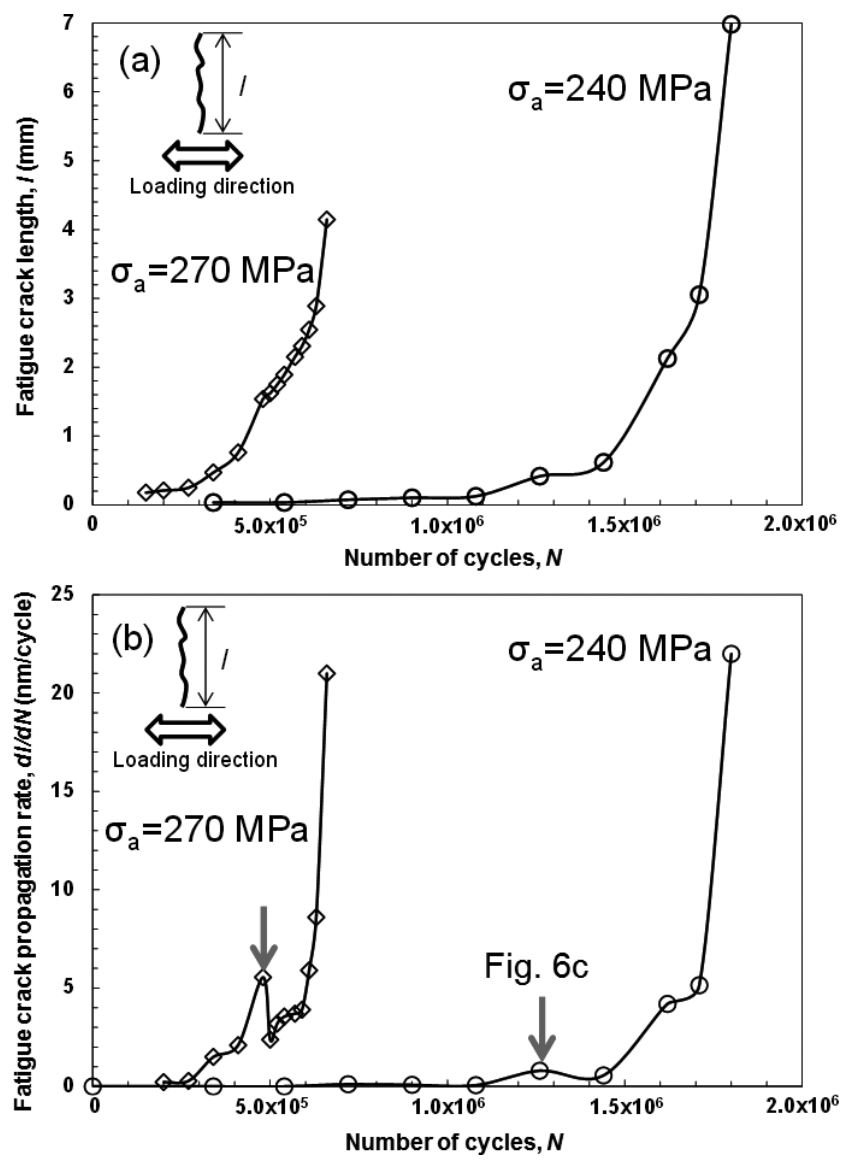

Fig. 4. (a) Fatigue crack length and (b) propagation rates plotted against number of cycles at the stress amplitudes of 240 and $270 \mathrm{MPa}$.

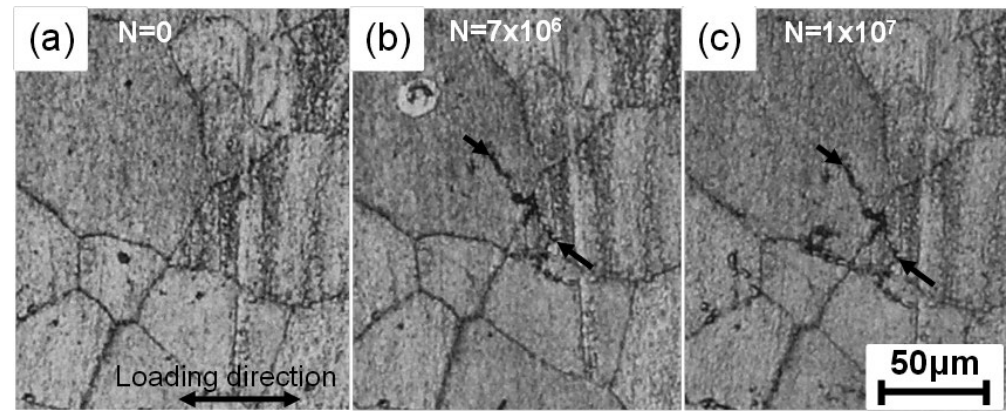

Fig. 3. Replica images showing non-propagating fatigue crack at the fatigue limit (210 MPa). (a) 0 cycle. (b) $7 \times 10^{6}$ cycles. (c) $1 \times 10^{7}$ cycles. 
cracks were initiated, as shown in Figs. 5(a) and 5(b). The intergranular cracks stem from plastic strain localization as discussed above. The transgranular cracks also would arise from plastic strain localization, since the transgranular fatigue in ductile materials is attributable to local straining in microstructurally weak regions. The number of fatigue cracks increased with increasing the number of cycles, and the primary crack initiation sites was grain boundaries. Since carbon enhances the grain boundary strength/hardness, ${ }^{29)}$ the ease of intergranular crack initiation can be attributed to the relatively low grain boundary strength, owing to the low amount of solute carbon in the grain boundaries in the quenched steel; this is in contrast to general annealed carbon steels that exhibit carbon segregation in the grain boundaries. ${ }^{30-32)}$ Actually, some annealed low carbon steels with similar grain sizes (or even with a larger grain size) have been reported to show transgranular crack initiation. ${ }^{33,34)}$ Namely, the effect reducing the grain boundary strength is considered to assist the cracking on grain boundaries which are significantly damaged by localization of plastic strain.

Note that the fatigue crack propagation rate increased discontinuously at some stages during cycling, as indicated by the red arrows in Fig. 4(b). These sudden increases in the crack propagation rate were caused by the coalescence of the fatigue cracks, as shown in Figs. 6(a)-6(c). The dominant fatigue crack propagation path was grain boundaries. In
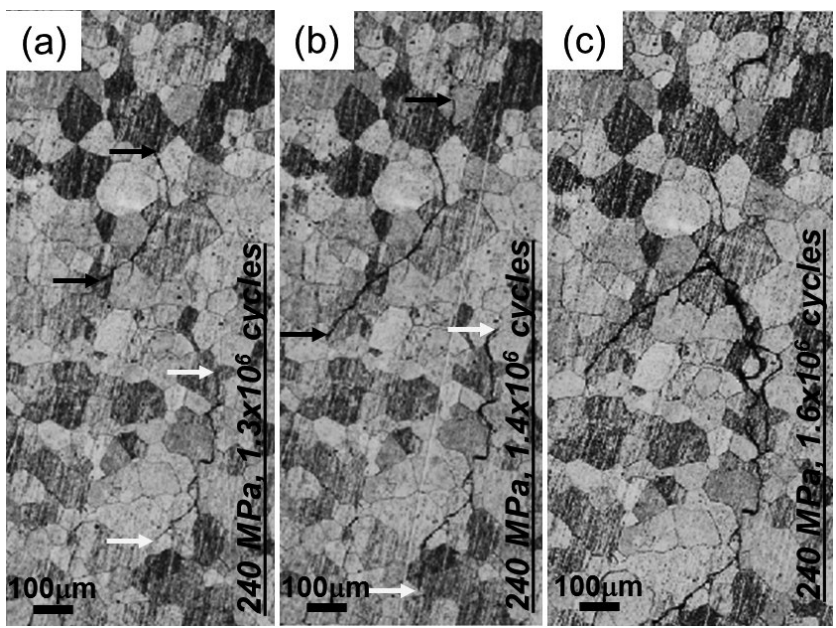

Fig. 6. (a, b) fatigue crack propagation and (c) its associated coalescence at the stress amplitude of $240 \mathrm{MPa}$. The yellow and red arrows indicate main and sub crack tips, respectively. contrast, most of transgranular cracks stopped to propagate. Even at $270 \mathrm{MPa}$, a few fatigue cracks remained in the grain interiors, as shown in Figs. 7(a) and 7(b). However, the fatigue cracks branched to the grain boundaries, resulting in the further propagation of the main crack. More specifically, the main propagation path was through the grain boundaries at every stress amplitude above the fatigue limit. Further, intergranular crack propagation did not stop till specimen failure or changing the path to the grain interior. The ratio of the extent of intergranular propagation with respect to the extent of transgranular propagation of the main crack at 240

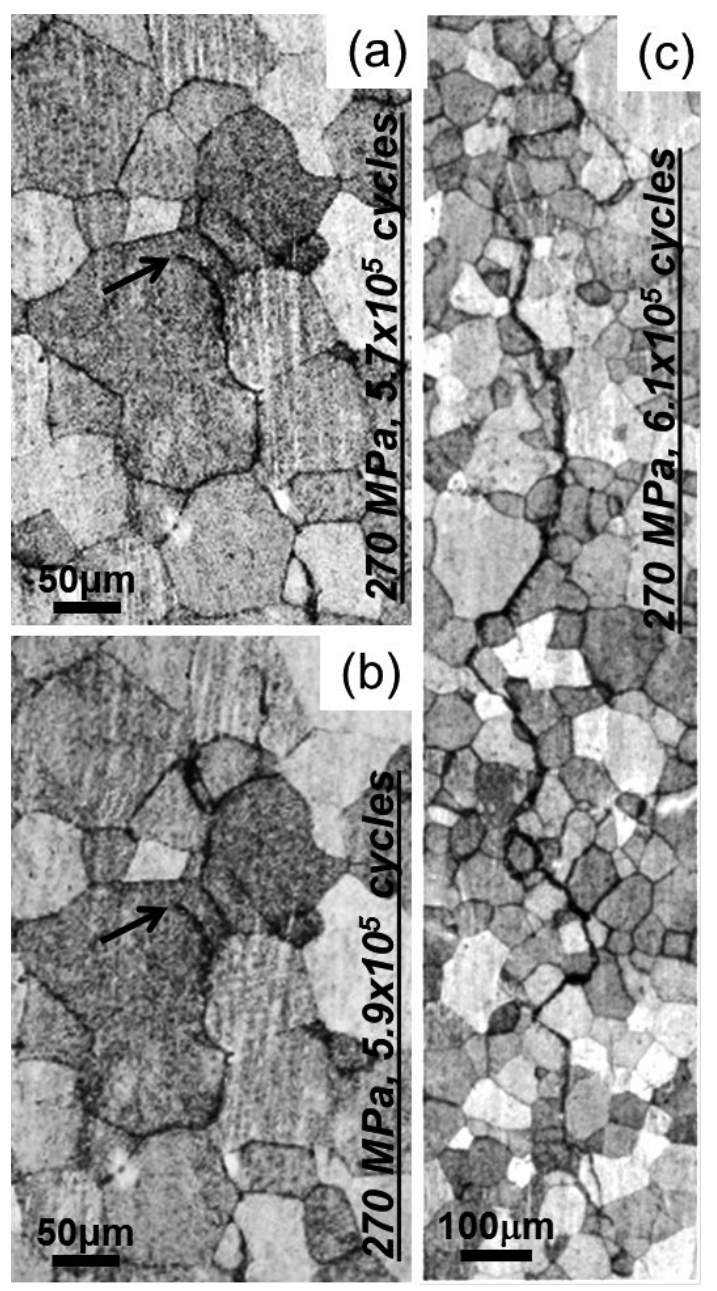

Fig. 7. (a, b) Non-propagating fatigue crack phenomenon in the grain interior, and (c) intergranular fatigue crack propagation at the stress amplitude of $270 \mathrm{MPa}$.

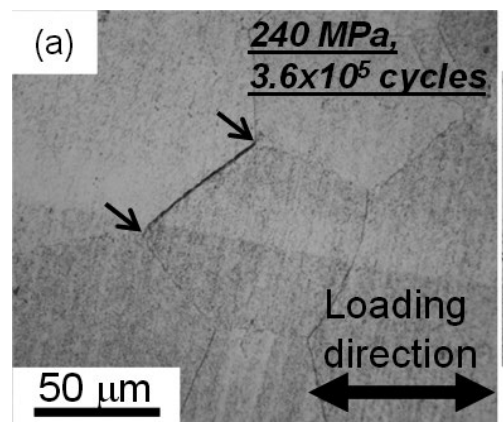

(b)

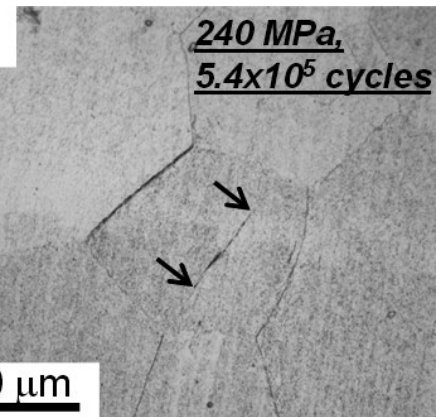

Fig. 5. Replica images showing (a) intergranular $\left(\mathrm{N}=3.6 \times 10^{5}\right)$ and (b) transgranular $\left(\mathrm{N}=5.4 \times 10^{5}\right)$ fatigue crack initiation at the stress amplitude of $240 \mathrm{MPa}$. Both view fields are identical. 
MPa was $67 \%$ and increased to $75 \%$ at $270 \mathrm{MPa}$, as shown in Fig. 7(c). It is likely that intergranular crack propagation occurs owing to the repeated initiation of cracks and their coalescence, which is associated with plastic strain localization at the crack tips, and not because of successive crack blunting and resharpening. ${ }^{35,36)}$ In other words, the intergranular cracking stems from strain-induced damage formation, not from slip-related change of the crack shape. This is because grain boundaries do not have a specific geometrical relationship with slip deformation, which is required for the blunting and resharpening of cracks. Thus, the fatigue crack propagation is primarily caused by the macroscopic coalescence of cracks, a phenomenon that depends on crystallographic characteristics (Figs. 6(a)-6(c)), as well as the microscopic coalescence of the cracks initiated repeatedly in the vicinity of the tip of the main crack, as mentioned above.

Figures 8 and 9 show a set of fractographs obtained at $240 \mathrm{MPa}$. The fracture surface shown in Fig. 8 consists of

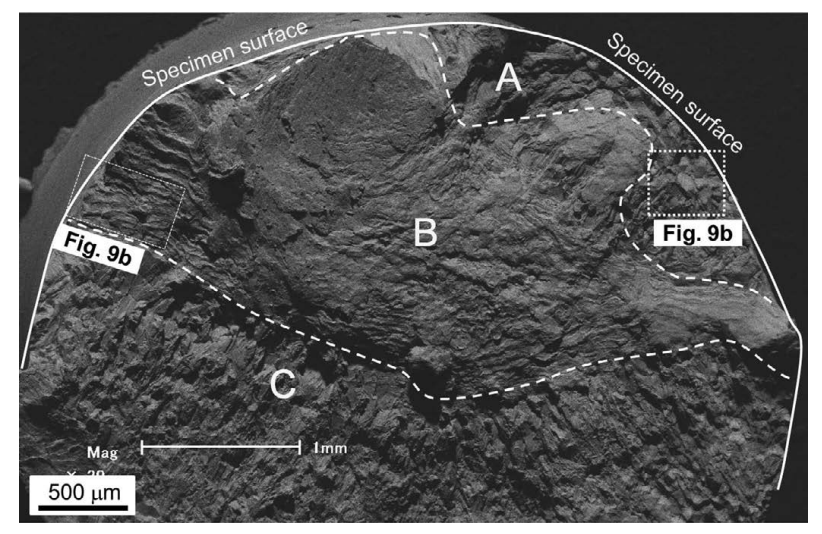

Fig. 8. Fracture surface at the stress amplitude of $240 \mathrm{MPa}$.
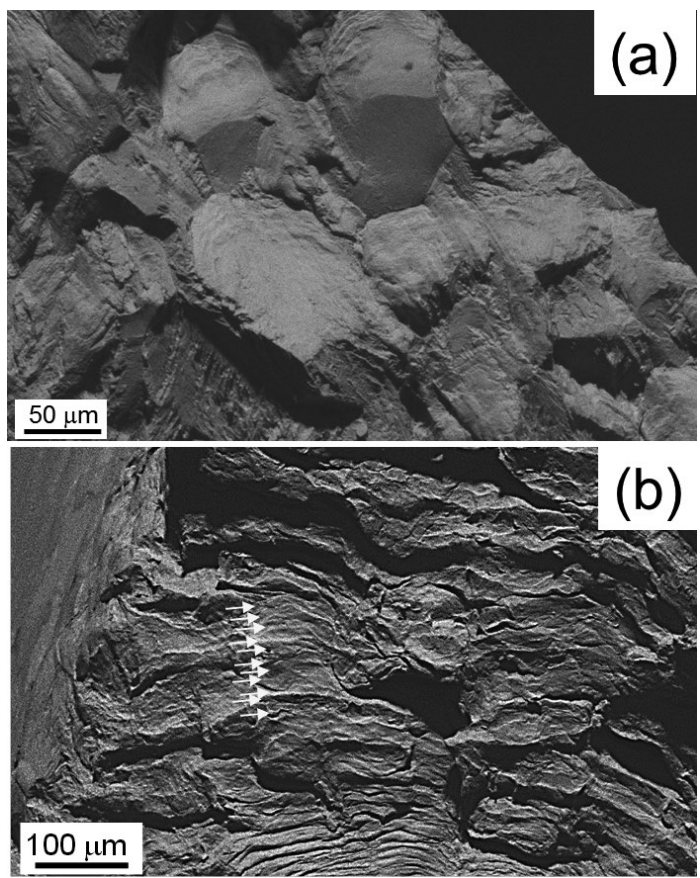

Fig. 9. Magnified images showing (a) intergranular feature and (b) fatigue striations, which correspond to the regions outlined by the yellow dashed lines in Fig. 8. The yellow arrows in Fig. 9(b) indicate examples of fatigue striations. three parts, which are denoted as A, B, and C. Part A corresponds to the area near the specimen surface and exhibited an intergranular feature, as can be seen from Fig. 9(a). This intergranular feature is the result of intergranular crack initiation and propagation shown in Figs. 5(a) and 6. No clear striations were observed in the intergranularly cracked regions. This fact supports the conclusion that intergranular crack propagation occurs through repeated crack initiation and not because of crack blunting and resharpening. In contrast, the fatigue striation observed in Fig. 9(b) is evidence of the occurrence of crack blunting and resharpening, ${ }^{35,36)}$ indicating that transgranular propagation as the rest of the propagation path can be explained by the conventional mechanism. Thus, both repeated crack initiation and the conventional mechanism are responsible for crack propagation in the investigated steel. However, there is an important difference between the two propagation modes in terms of the nonpropagating cracks. Repeated crack initiation does not cease, since cracks are initiated everywhere, including at the grain boundaries as well as the crack tips; this phenomenon is not significantly affected by crack closure mechanisms such as plasticity-induced crack closure. ${ }^{37)}$ On the other hand, crack blunting and resharpening are retarded by plasticity-induced crack closure and local hardening owing to strain aging at the crack tip. As a result, intergranular crack propagation becomes the dominant crack

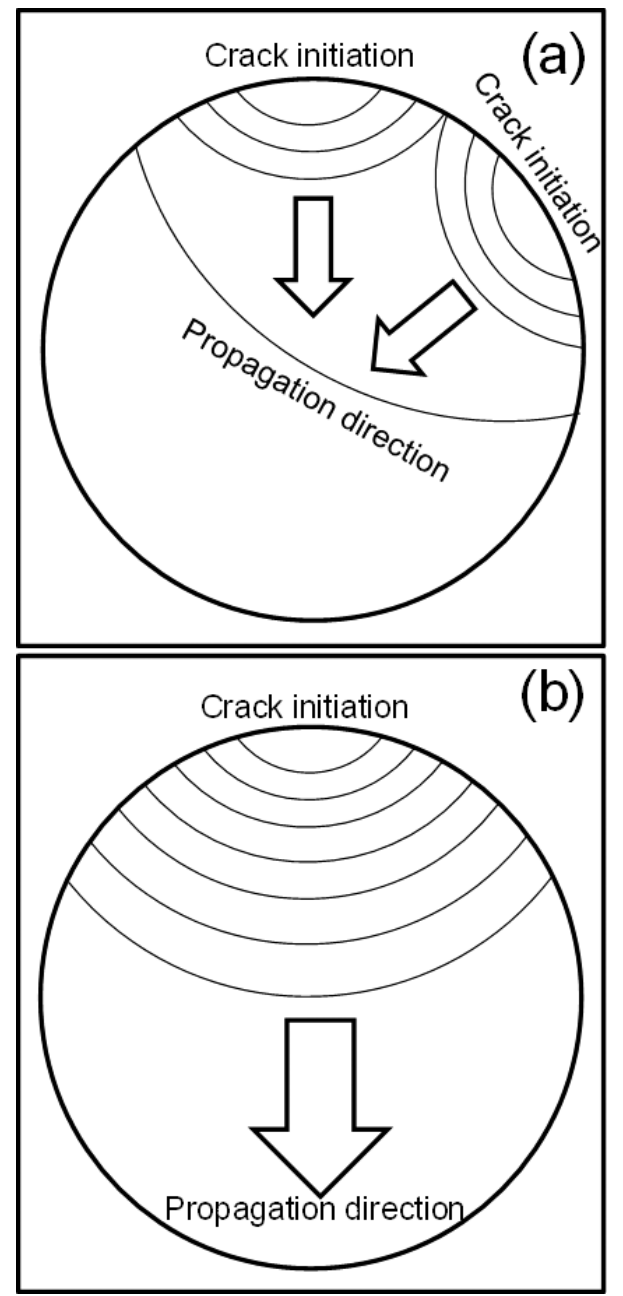

Fig. 10. Schematic illustrations of (a) the present fracture surface and (b) general fracture surface. 
growth mechanism.

The crack propagation process until failure is also noted in terms of the fractographic feature. The feature corresponding to part A in Fig. 8 indicates that the fatigue crack propagated from at least two crack initiation sites (Fig. 10(a)), in contrast to the general fatigue-related surface fractures resulting from crack propagation from a single crack initiation site (Fig. 10(b)). Since a considerable number of cracks were initiated on the specimen surface in the case of the investigated steel, it is likely that multiple cracks propagated and coalesced, resulting in the feature seen in part A. At the end of the first stage, the crack had already become 5 $\mathrm{mm}$ in length, which is close to the maximum crack length just before failure $(7 \mathrm{~mm})$, as can be seen from Fig. 4(a). Thus, it can be concluded that this process dominates the fatigue life of the steel. Next, the crack propagated rapidly, owing to the stress concentration at the connection point between the cracks; this phenomenon corresponds to part B. The maximum crack length of $7 \mathrm{~mm}$ was reached in this stage. Finally, the specimen fractured owing to tearing by a tensile stress; this corresponded to part C.

\section{Conclusion}

To conclude, the essential effects of solute carbon on short fatigue crack propagation were examined using a water-quenched Fe-0.018C binary ferritic steel, which had less carbon segregation and no second phase. We found that nonpropagating fatigue cracks occur in the investigated steel even at stress amplitudes greater than the fatigue limit, when the fatigue cracks propagate to grain interiors. However, the occurrence of intergranular fatigue cracking causes the further propagation of the cracks to grain boundaries through crack branching. These facts indicate that the solute carbon has a significant effect on short fatigue crack propagation owing to strain age hardening at the crack tips within grain interiors. In addition, when the stress amplitude was increased from the fatigue limit to a higher level every $10^{7}$ cycles, both fatigue crack initiation and propagation were totally suppressed, because of strain age hardening (coaxing effect). This fact indicates that the intergranular fatigue crack initiation is caused by localization of plastic strain and that pre-cyclic-strain-induced strain age hardening can increase resistance to the intergranular fatigue crack initiation as well as the propagation.

\section{REFERENCES}

1) H. Nisitani, M. Goto and N. Kawagoishi: Eng. Fract. Mech., 41 (1992), 499.

2) R. O. Ritchie and J. Lankford: Mater. Sci. Eng., 4 (1986), 11.

3) K. J. Miller: Fatigue Fract. Eng. M., 10 (1987), 75.

4) D. L. Mcdowell: Int. J. Fracture, 80 (1996), 103.

5) Y. Murakami and M. Endo: Int. J. Fatigue, 16 (1994), 163.

6) K. Tokaji, T. Ogawa, Y. Harada and Z. Ando: Fatigue Fract. Eng. M., 9 (1986), 1.

7) K. Tanaka, Y. Nakai and M. Yamashita: Int. J. Fracture, 17 (1981), 519.

8) R. O. Ritchie: Mater. Sci. Eng. A, 103 (1988), 15.

9) A. K. Vasudeven, K. Sadananda and N. Louat: Mater. Sci. Eng. A, 188 (1994), 1

10) R. P. Gangloff: Metall. Trans. A, 16 (1985), 953.

11) K. J. Miller: Fatigue Fract. Eng. M., 5 (1982), 223.

12) C. Laird: Fatigue crack propagation ed. by J. C. Grosskreutz, American Society for Testing and Materials, Philadelphia, PA, (1967), 131.

13) G. Bertolino, V. Doquet and M. Sauzay: Int. J. Fatigue, 27 (2005), 471.

14) M. Herbig, A. King, P. Reischig, H. Proudhon, E. M. Lauridsen, J. Marrow, J.-Y. Buffière and W. Ludwig: Acta Mater., 59 (2011), 590.

15) G. M. Sinclair: Proc. Am. Soc. Test. Mat., 52 (1952), 743.

16) G. Oates and D. V. Wilson: Acta Metall., 12 (1964), 21.

17) T. Yakushiji, M. Kage and H. Nisitani: Trans. Jpn. Soc. Mech. Eng. A, 62 (1996), 82.

18) Z.-J. Xi, M. Koyama, Y. Yoshida, N. Yoshimura, K. Ushioda and H. Noguchi: Philos. Mag. Lett., 95 (2015), 384.

19) J. B. Gough: The Fatigue of Metals, Scott, Greenwood and Son, London, (1926), 108

20) J. B. Kommers: Proc. ASTM, 38 (1938), Part 2, 249.

21) J. A. Bennett: Natl. Bur. Standards (US), Research Paper, 37 (1946), 123.

22) G. M. Sinclair: Proc. ASTM, 52 (1952), 743

23) M. Akita, M. Nakajima, Y. Uematsu, K. Tokaji and J.-W. Jung: Fatigue Fract. Eng. M., 35 (2012), 1095.

24) M. Hayashi and K. Enomoto: Int. J. Fatigue, 28 (2006), 1626.

25) H. Nishitani and S. Nishida: Trans. Jpn. Soc. Mech. Eng. 39 (1973), 1385.

26) H. Nishitani and Y. Yamaguchi: Trans. Jpn. Soc. Mech. Eng. 45 (1979), 260

27) Y. Murakami, Y. Tazunoki and T. Endo: Metall. Trans. A, 15A (1984), 2029.

28) S. Ishihara and A. J. McEviliy: Scr. Mater. 40 (1999), 617

29) R. Wu, A. J. Freeman and G. B. Olson: Phys. Rev. B, 53 (1996), 7504 .

30) H. Hänsel and H. J. Grabke: Scr. Metall., 20 (1986), 1641.

31) J. M. Papazian and D. N. Beshers: Metall. Trans., 2 (1971), 497.

32) M. Herbig, D. Raabe, Y. J. Li, P. Choi, S. Zaefferer and S. Goto: Phys. Rev. Lett., 112 (2014), 126103.

33) A. Otsuka, M. Mori and T. Miyata: Eng. Fract. Mech., 7 (1975), 429.

34) K. Asami and M. Terasawa: Zairyo, 30 (1981), 803.

35) C. Laird and G. C. Smith: Philos. Mag., 7 (1962), 847.

36) C. Laird and R. De La Veaux: Metall. Trans. A, 8A (1977), 657.

37) W. Elber: Damage Tolerance in Aircraft Structures, ed. by M.S. Rosenfeld, American Society for Testing and Materials, Philadelphia, PA, (1971), 230 